\title{
Arteriovenous malformations of the brain: natural history in unoperated patients
}

\author{
PM CRAWFORD, CR WEST, * DW CHADWICK, MDM SHAW \\ From the Mersey Regional Centre for Medical and Surgical Neurology, Walton Hospital, and the Department \\ of Medicine (Biostatistics), ${ }^{*}$ University of Liverpool, Liverpool, UK
}

SUMmaRY Two-hundred and seventeen patients from a total population of 343 patients with arteriovenous malformations, were managed without surgery. Follow up was for a mean of 10.4 years. Using life survival analyses, there was a $42 \%$ risk of haemorrhage, $29 \%$ risk of death, $18 \%$ risk of epilepsy and a $27 \%$ risk of having a neurological handicap by 20 years after diagnosis in unoperated patients.

Arteriovenous malformations were first recognised by the ancient Egyptians in $1500 \mathrm{BC}^{1}$ and they were known to both ancient Roman and Arab worlds. ${ }^{2}$ In Western medicine, Hunter described extracranial arteriovenous malformations in 1757 , but it was not until 1863 that Virchov reported the pathological appearances of intracranial arteriovenous malformations. $^{3}$ The first clinical diagnosis of an arteriovenous malformation has been attributed to Steinhal in $1895 .^{3}$

Attempts at operative intervention began early, when in 1908 Krause tried unsuccessfully to ligate the feeding blood vessels of an arteriovenous malformation. ${ }^{4}$ In 1928 Dandy $^{5}$ reported in nine patients the effect of coagulation of blood vessels, or partial excision of the arteriovenous malformation, Cushing and Bailey ${ }^{6}$ discussed eight surgically managed patients. The introduction of cerebral angiography by Moniz in 1927 revolutionised the diagnosis and treatment of such lesions. ${ }^{3}$ Olivacrona and Ladenheim $^{2}$ and Tonnis ${ }^{7}$ pioneered their surgical removal, demonstrating that excision could be accomplished without a prohibitive morbidity or mortality. This emphasis on surgical treatment for arteriovenous malformations has made it difficult to determine the natural history of the disorder.

Many centres have examined the results of surgery (table 1). However, patients referred for treatment are frequently a selected population. Assessment of outcome after surgical treatment is rarely compared with conservative management

Address for reprint requests: Dr DW Chadwick, Walton Hospital, Rice Lane, Liverpool L9 1AE, UK.

Received 8 February 1985 and in revised form 12 May 1985. Accepted 17 May 1985 especially in those presenting without haemorrhage. The number of untreated patients in reported series is usually too small to draw firm conclusions about the natural history of untreated arteriovenous malformations. There is generally a short follow up and only one study has used life survival analyses to assess outcome. The other studies have assessed risks as an absolute figure based on varying, often undefined, periods of follow up.

Before assessing the results of therapy the natural history of the condition must be determined. In particular the following questions require an answer: (1) What is the risk of subsequent haemorrhage? (2) What is the likelihood of developing a late neurological deficit? (3) What is the risk of developing de novo epilepsy? (4) What is the risk of death? (5) What factors influence these risks?

We report a retrospective survey of the natural history of 217 patients who did not undergo any form of surgery or irradiation from an unselected

Table 1 Summary of studies of arteriovenous malformations

\begin{tabular}{|c|c|c|c|c|}
\hline Author & & $\begin{array}{l}\text { Total } \\
\text { patients } \\
n\end{array}$ & $\begin{array}{l}\text { No } \\
\text { excision } \\
n\end{array}$ & Follow up \\
\hline $\begin{array}{l}\text { Svien } \\
\text { Perret }^{12} \\
\text { Troupp }^{14} \\
\text { Moody }^{18} \\
\text { Forster }^{14} \\
\text { Guidetti }^{24} \\
\text { Parkinson }^{25} \\
\text { Pellettieri' }^{20} \\
\text { Graf }^{16} \\
\text { Fults }^{15}\end{array}$ & $\begin{array}{l}1961 \\
1966 \\
1969 \\
1970 \\
1972 \\
1980 \\
1980 \\
1980 \\
1983 \\
1984\end{array}$ & $\begin{array}{l}95 \\
502 \\
137 \\
105 \\
150 \\
145 \\
100 \\
169 \\
191 \\
131\end{array}$ & $\begin{array}{r}68 \\
232^{*} \\
137 \\
6 \\
35 \\
50 \\
4 \\
47 \\
191 \\
83\end{array}$ & $\begin{array}{l}\text { median } 15 \mathrm{yr} \\
\text { median } 5 \mathrm{yr} \\
\text { median } 3 \mathrm{yr} \\
\text { mean } 15 \mathrm{yr} \\
2-25 \mathrm{yr} \\
4-26 \mathrm{yr} \\
\text { mean } 10 \cdot 5 \mathrm{yr} \\
\text { mean } 3 \mathrm{yr} \\
\text { mean } 8 \mathrm{yr}\end{array}$ \\
\hline
\end{tabular}

*numbers extrapolated from text. 
population of 343 patients with arteriovenous malformations.

\section{Methods}

Three-hundred and forty-three patients with arteriovenous malformations were diagnosed at the Mersey Regional Department of Medical and Surgical Neurology between 1941 and 1948. The department provides a neurological and neurosurgical service for the counties of Merseyside, Clwyd, Gwynedd, parts of Cheshire and Lancashire and the Isle of Man. It is the only neurological and neurosurgical centre serving this population of approximately 3.2 million. Two-hundred and seventeen of the 343 patients were managed non-surgically. The patients were identified by means of the neurosurgical diagnostic index and from neurological records. Patients were traced from hospital notes and by writing to their general practitioners, asking about the development of epilepsy, neurological signs, or haemorrhage. If a patient was no longer registered with the practice, an attempt to find the new GP was made by writing to the local Family Practitioner Committee, but if dead, a death certificate was obtained from the appropriate registrar of Births and Deaths.

Results were analysed using $\chi^{2}$ test, Fisher-Irwin Exact test, $\chi^{2}$ for trend, ${ }^{8}$ Lee-Desu statistics, ${ }^{9}$ and life survival analyses $^{10}$ as appropriate. A probability of less than 0.05 was accepted as significant.

\section{Patient characteristics}

Patients were aged from 2 months to 67 years. Over 50\% of patients were diagnosed before the age of $30 ; 188$ were male, 155 female, a ratio of $1 \cdot 22: 1$ There was no difference in the operative rate between the sexes (120 men and 97

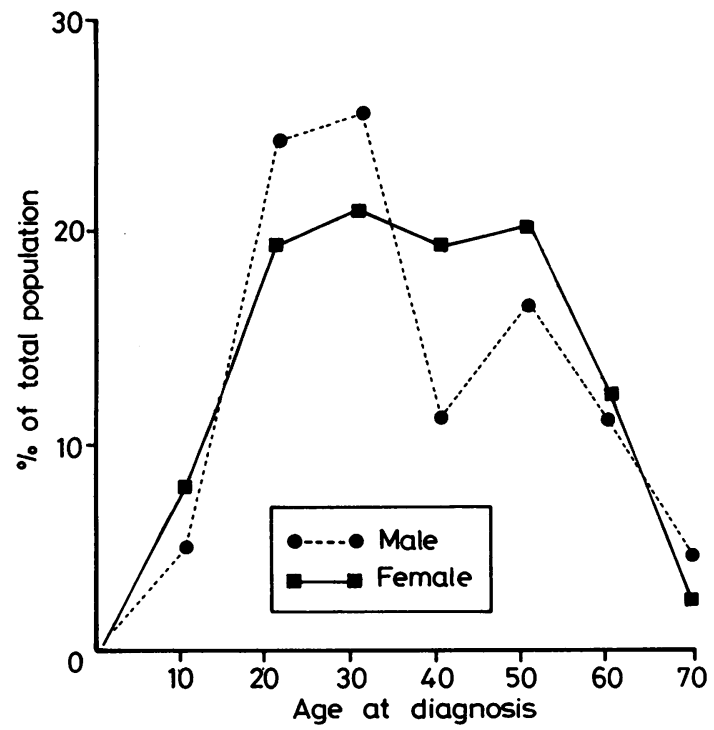

Fig 1 Age distribution at diagnosis of 198 males and 155 females presenting with haemorrhage. The percentages expressed are for the male and female groups independently.
Table 2 Symptom complex at diagnosis

\begin{tabular}{lccc}
\hline & All & Treated & Untreated \\
\hline n & 343 & 126 & 217 \\
Group 1 (haemorrhage) & $72 \%$ & $85 \%$ & $64 \%$ \\
Group 2 (epilepsy) & $18 \%$ & $8 \%$ & $23 \%$ \\
Group 3 (neurological signs) & $7 \%$ & $4 \%$ & $8 \%$ \\
Group 4 (others) & $3 \%$ & $3 \%$ & $4 \%$ \\
\hline
\end{tabular}

women were managed conservatively). Interestingly one in four of women aged between 20 and 29 years, presenting with haemorrhage, were pregnant. More women presented as a result of haemorrhage in the third decade than did men, emphasising that pregnancy may increase the risk of haemorrhage (fig 1).

\section{Symptoms at diagnosis}

In the analysis of results, the patients have been grouped according to their symptom complex at diagnosis:

Group 1: Haemorrhage \pm epilepsy \pm neurological signs

Group 2: Epilepsy \pm neurological signs

Group 3: Neurological signs

Group 4: Other

Patients in Group 4 presented with miscellaneous problems including two infants with heart failure, four patients with intracranial bruits, three with headaches, two with subarachnoid haemorrhage secondary to a ruptured aneurysm, and patients diagnosed as a result of investigation of encephalitis, migraine or a road traffic accident. The mode of presentation for all patients and untreateof patients is summarised in table 2 .

Eighty-three of 343 patients had symptoms for at least a year prior to diagnosis. Thirty-seven patients who pres sented with haemorrhage had epilepsy before diagnosis. Inf 19 of these patients epilepsy was the first symptom of theif arteriovenous malformation, but the correct diagnosis was not made until haemorrhage occurred. The onset of epilepsy ranged from 1 to 30 years prior to diagnosis the mean being 9 years. The other 18 patients developed epilepsy between the onset of their first symptom and diagnosis. Twenty-eight patients suffered a haemorrhage before the admission for diagnosis. Four of these patients had had more than one haemorrhage. The timing of the initial haemorrhage varied from a few days to 22 years prior to diagnosis and was evenly distributed throughout this time interval.

Table 3 Neurological signs antedating diagnosis in 343 patients

\begin{tabular}{llll}
\hline & \multicolumn{2}{c}{ Diagnostic symptom } \\
\cline { 2 - 4 } & $\begin{array}{l}\text { Group 1 } \\
\text { haemorrhage }\end{array}$ & $\begin{array}{l}\text { Group 2 } \\
\text { epilepsy }\end{array}$ & $\begin{array}{l}\text { Group 3 } \\
\text { neurological } \\
\text { signs }\end{array}$ \\
\hline Hemiparesis & 6 & 12 & 9 \\
Hydrocephalus & 0 & 1 & 2 \\
dementia & 0 & 1 & 4 \\
Papilloedema & 0 & 1 & 6 \\
Visual field defects & 0 & 1 & 0 \\
Mental subnormality & 0 & 4 & 2 \\
Other & 0 & 20 & 23 \\
Total & 6 & &
\end{tabular}


Twenty-seven out of the 61 patients presenting with epilepsy had had epilepsy for 1 to 30 years prior to diagnosis (mean 9 years). Twenty patients presenting with epilepsy as their major diagnostic symptom also had neurological signs. Physical signs antedating diagnosis in these three diagnostic groups are summarised in table 3.

\section{Characteristics of the arteriovenous malformation}

In almost all cases the following figures refer to the angiographic appearances of the arteriovenous malformations, and are only rarely based on CT findings alone.

Forty-three per cent were in the right hemisphere, $39 \%$ in the left, and $11 \%$ crossed the midline. There was an excess of left hemisphere arteriovenous malformations amongst patients presenting with epilepsy as opposed to haemorrhage but this difference is not statistically significant (table 4).

The size of an arteriovenous malformation was recorded as small if the diameter was less than $2 \mathrm{~cm}$ and large if greater than $6 \mathrm{~cm}$ (table 5). There was an excess of small arteriovenous malformations in patients presenting with haemorrhage, and an excess of large lesions amongst patients presenting with epilepsy $(p<0.05)$.

The depth of an arteriovenous malformation was classified as either deep or superficial, depending on the radiography report (table 6). In many circumstances angiographic reports lacked sufficient clarity for classification. The undetermined group is likely to comprise a large number of extensive arteriovenous malformations that include both deep and superficial components. There appears to be an excess of patients with deep arteriovenous malformations presenting with haemorrhage as compared to epilepsy $(p<0.05)$.

The majority of arteriovenous malformations were supratentorial $(90 \%)$, the parietal lobe being most frequently

Table 4 Side of arteriovenous malformation

\begin{tabular}{lccc}
\hline & All & Treated & Untreated \\
\hline $\mathbf{n}$ & 343 & 126 & 217 \\
Right & $43 \%$ & $53 \%$ & $47 \%$ \\
Left & $39 \%$ & $39 \%$ & $40 \%$ \\
Bilateral & $11 \%$ & - & $17 \%$ \\
Unknown & $7 \%$ & $8 \%$ & $7 \%$ \\
\hline
\end{tabular}

Table 5 Size of arteriovenous malformation

\begin{tabular}{lccc}
\hline & All & Treated & Untreated \\
\hline $\mathrm{n}$ & 343 & 126 & 216 \\
Large & $43 \%$ & $28 \%$ & $52 \%$ \\
Medium & $6 \%$ & $6 \%$ & $6 \%$ \\
Small & $18 \%$ & $25 \%$ & $13 \%$ \\
Undetermined & $33 \%$ & $40 \%$ & $29 \%$ \\
\hline
\end{tabular}

Table 6 Depth of arteriovenous malformation

\begin{tabular}{lccc}
\hline & All & Treated & Untreated \\
\hline $\mathrm{n}$ & 343 & 126 & 217 \\
Deep & $31 \%$ & $20 \%$ & $37 \%$ \\
Superficial & $12 \%$ & $20 \%$ & $7 \%$ \\
Undefined & $56 \%$ & $58 \%$ & $55 \%$ \\
\hline
\end{tabular}

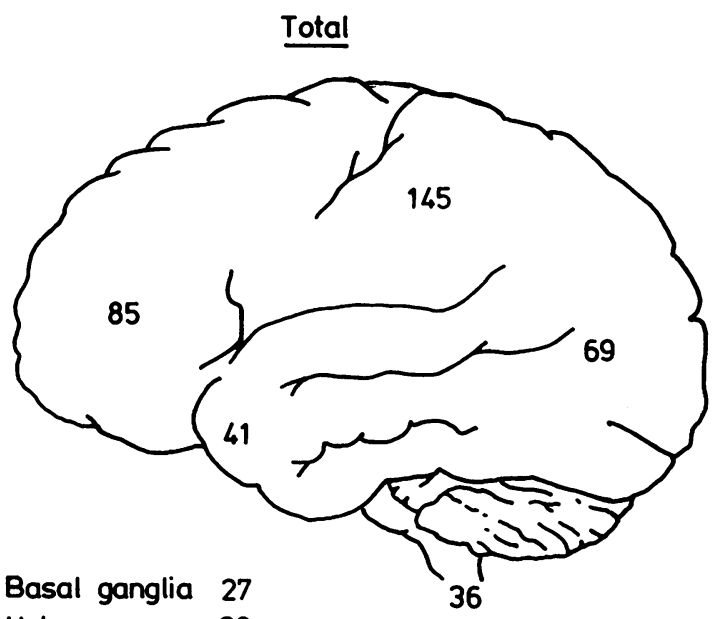

Unknown 20

Fig 2 Distribution of arteriovenous malformations in 343 patients.

involved (fig 2). The lobes of the brain involved in the arteriovenous malformation did not influence the mode of presentation.

Twenty-four of our patients $(7 \%)$ had aneurysms as well as an arteriovenous malformation. Five patients had multiple aneurysms and in 18 patients $(75 \%)$ the aneurysm was situated on a feeding blood vessel leading to the arteriovenous malformation.

\section{Comparison of surgically and non-surgically treated patients}

Before attempting to define the natural history of untreated arteriovenous malformations it is necessary to determine whether those patients who did not receive surgical treatment are representative of the group as a whole.

There was no difference between sex ratio or age of patients managed surgically or conservatively $\left(\chi^{2}\right.$ trend $p<$ 0.2 ) (table 7). In patients managed conservatively, the left hemisphere was more frequently involved and the arteriovenous malformation was more likely to cross the midline $(p<0.001)$. Medically managed arteriovenous malformations were more frequently larger $(p<0.05)$, deeper $(p<0.05)$ and more posterior $(p<0.05)$ in situation than arteriovenous malformations receiving surgical treatment. Neurological disabilities at diagnosis were simi-

Table 7 Age at diagnosis: treatment

\begin{tabular}{lll}
\hline Age $(y r)$ & Conservative & Surgery \\
\hline $0-9$ & 16 & 6 \\
$10-19$ & 46 & 25 \\
$20-29$ & 41 & 35 \\
$30-39$ & 34 & 20 \\
$40-49$ & 41 & 16 \\
$50-59$ & 36 & 14 \\
$60-69$ & 11 & 1 \\
- & & \\
\hline$\chi^{2}$ trend $\mathrm{p}<0.2$. & &
\end{tabular}


Table 8 Hunt Hess grades

\begin{tabular}{lcc}
\hline & Untreated & Treated \\
\hline Unknown & $21(15 \%)$ & $10(9 \%)$ \\
Deep coma & $11(8 \%)$ & $13(12 \%)$ \\
Major neurological deficit & $14(10 \%)$ & $16(15 \%)$ \\
Minor neurological deficit & $44(31 \%)$ & $39(36 \%)$ \\
Moderate/severe headache & $39(28 \%)$ & $23(21 \%)$ \\
Asymptomatic & $11(8 \%)$ & $6(6 \%)$ \\
Total & 140 & 107 \\
\hline
\end{tabular}

$\chi^{2}$ trend $\mathrm{p}<0.1$

Table 9 Year of diagnosis: mode of treatment

\begin{tabular}{lcccc}
\hline Yeax & $\begin{array}{l}\text { Conservative } \\
\text { treatment }\end{array}$ & $\begin{array}{l}\text { Surgical } \\
\text { treatment }\end{array}$ & Radiotherapy & Total \\
\hline $1940-44$ & 1 & 0 & 0 & 1 \\
$1945-49$ & 1 & 2 & 0 & 3 \\
$1950-54$ & 17 & 4 & 0 & 21 \\
$1955-59$ & 23 & 12 & 5 & 40 \\
$1960-64$ & 35 & 12 & 1 & 48 \\
$1965-69$ & 43 & 21 & 1 & 65 \\
$1970-74$ & 44 & 25 & 2 & 69 \\
$1975-79$ & 32 & 25 & 0 & 57 \\
$1980-84$ & 21 & 16 & 0 & 37 \\
Total & 217 & 117 & 9 & 343 \\
\hline
\end{tabular}

$\chi^{2} \mathrm{p}<0.05$.

lar in patients managed conservatively or surgically ( $p<$ $0 \cdot 1)$ and in patients presenting with haemorrhage, Hunt Hess Grades were also similar (table 8).

Patients presenting in the latter years of this study were less likely to be managed conservatively (table 9). This was true if the patient presented with haemorrhage. For patients presenting with epilepsy the converse was true. All patients with epilepsy diagnosed in the last ten years have been managed conservatively. There was no difference in the duration of follow up between the two groups.

These differences between patients managed conservatively and those treated surgically are important to bear in mind when attempting to apply the results of our follow up data to a less selected group of patients with arteriovenous malformations. The differences simply reflect surgical inaccessibility.

\section{Follow up of unoperated patients}

Patients were followed up for a median of 9 years (mean 10.4 years) after diagnosis (range 1 to 35 years). Seventysix per cent of all our patients were traced to death or 1984 (table 10). In patients in whom follow up was not complete, data up to the last attendance are included in our results. Life-survival analyses allow for variable or incomplete follow up.

Table 10 Follow up

\begin{tabular}{lccc}
\hline & $\begin{array}{l}\text { Alive } \\
1983 / 4\end{array}$ & Dead & $\begin{array}{l}\text { Lost to } \\
\text { follow up }\end{array}$ \\
\hline Group 1 haemorrhage & 70 & 32 & 38 \\
Group 2 epilepsy & 35 & 8 & 8 \\
Group 3 neurological signs & 9 & 4 & 5 \\
Group 4 other & 5 & 2 & 1 \\
Total & 119 & 46 & 52 \\
\hline
\end{tabular}

All subsequent percentages referred to in the text are actuarial percentages.

\section{Late treatment}

Although all the 217 patients were initially managed conservatively, 13 patients $(6 \%)$ underwent surgery at a later date. Nine patients had their arteriovenous malformations excised, three of whom developed de novo epilepsy postoperatively. Two patients were treated by embolisation of the arteriovenous malformation, one had clipping of feeding arteries, and another patient had insertion of a ventriculo-atrial shunt. Three of the 13 patients developed a postoperative neurological deficit, but in only one patient was this severe. A further patient, who presented initially as a result of a mild hemiparesis, died during an elective attempt to remove the arteriovenous malformation. All 13 patients are analysed as part of the non-operative group as this was the first post diagnosis management decision.

\section{Late haemorrhage}

The risk of subarachnoid haemorrhage during the 20 years following diagnosis was $42 \%$ (10 years-30\%) (fig 3 ). There may have been a slightly increased risk in the first two years after diagnosis but thereafter the risk was approximately $2 \%$ per annum. This risk varied depending on the symptoms at diagnosis (fig 4). If a patient presented with haemorrhage the risk of a further haemorrhage by 20 years was $51 \%$ (10 years $-36 \%$ ) compared to a risk of $33 \%$ (10 years $-17 \%)$ for patients with arteriovenous mal-o formations which had not bled $(p<0.001)$. If a patient had had more than one haemorrhage before diagnosis, there $\frac{\rho}{\Phi}$ was a $58 \%$ risk of another haemorrhage by 15 years afterฉ diagnosis, compared to $46 \%$ for patients who had presented with their first haemorrhage. This difference is not statistically significant. Epilepsy as a principal diagnosticoㅇㅇ symptom carried with it a lower risk of $30 \%$ (10 years $22 \%$ ), whilst only $8 \%$ of patients $(10$ years $-8 \%)$ withoㅡㅡ neurological deficit and no patients in whom the? arteriovenous malformation was a coincidental finding, had bled by 20 years after diagnosis.

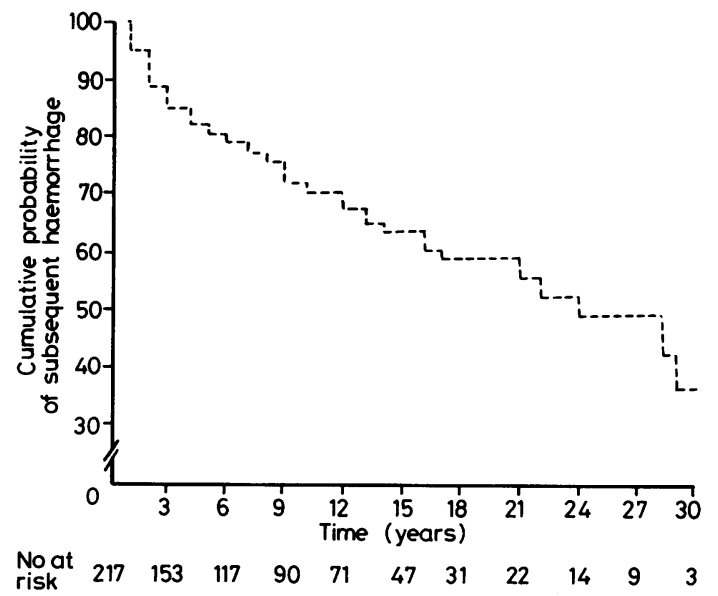

Fig 3 Risk of haemorrhage during follow up. 


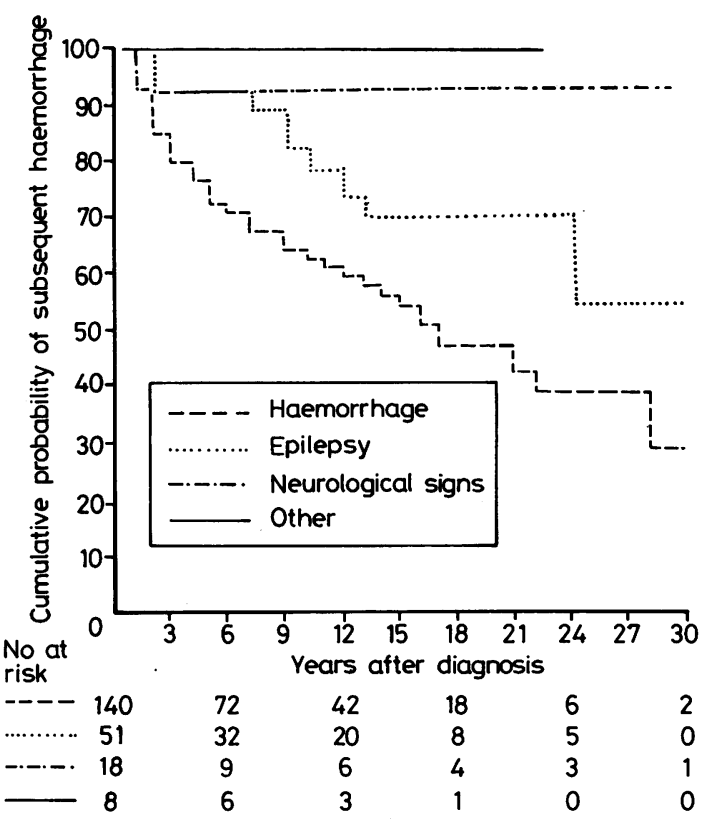

Fig 4 Risk of haemorrhage for symptom complex at diagnosis.

Seven patients had two haemorrhages after diagnosis, three patients had three haemorrhages, and another three patients had four or more haemorrhages during follow up.

Neither size nor depth of an arteriovenous malformation influenced the risk of subsequent haemorrhage (fig $5 \mathrm{a}$ and b). Parietal arteriovenous malformations have a reduced risk of subsequent haemorrhage; $32 \%$ by 20 years $(23 \%$ at 10 years) compared to arteriovenous malformations at other sites $(p<0.02)$. Arteriovenous malformations in both temporal and occipital lobes carried with them an increased risk of haemorrhage of $67 \%$ and $52 \%$ at 20 years, $36 \%$ and $42 \%$ at 10 years. This was significant at a one tailed level for temporal lobe arteriovenous malformations $(\mathrm{p}<0.05)$.

There was no difference in the risk of haemorrhage between the sexes. The patient's age at diagnosis was of importance as a risk factor for haemorrhage. Although there was no difference in diagnostic symptoms, the older the patient was at diagnosis, the greater the risk of haemorrhage during follow up ( $p<0.001)$. Eleven patients were over the age of 60 at the time of diagnosis; eight of these patients had a haemorrhage during follow up. They had a $89 \%$ risk of haemorrhage by 9 years compared to a $15 \%$ risk in the same period if aged 20 to 29 .

\section{Death}

By 20 years after diagnosis the risk of death from all causes was $29 \%$ ( $18 \%$ at 10 years) (fig 6). Nine patients died in hospital at the time of diagnosis; one as a result of status epilepticus, one from a bleed from a coexisting aneurysm; two died from a rehaemorrhage whilst awaiting operation; five patients died from their presenting haemorrhage, two of whom were diagnosed post mortem.
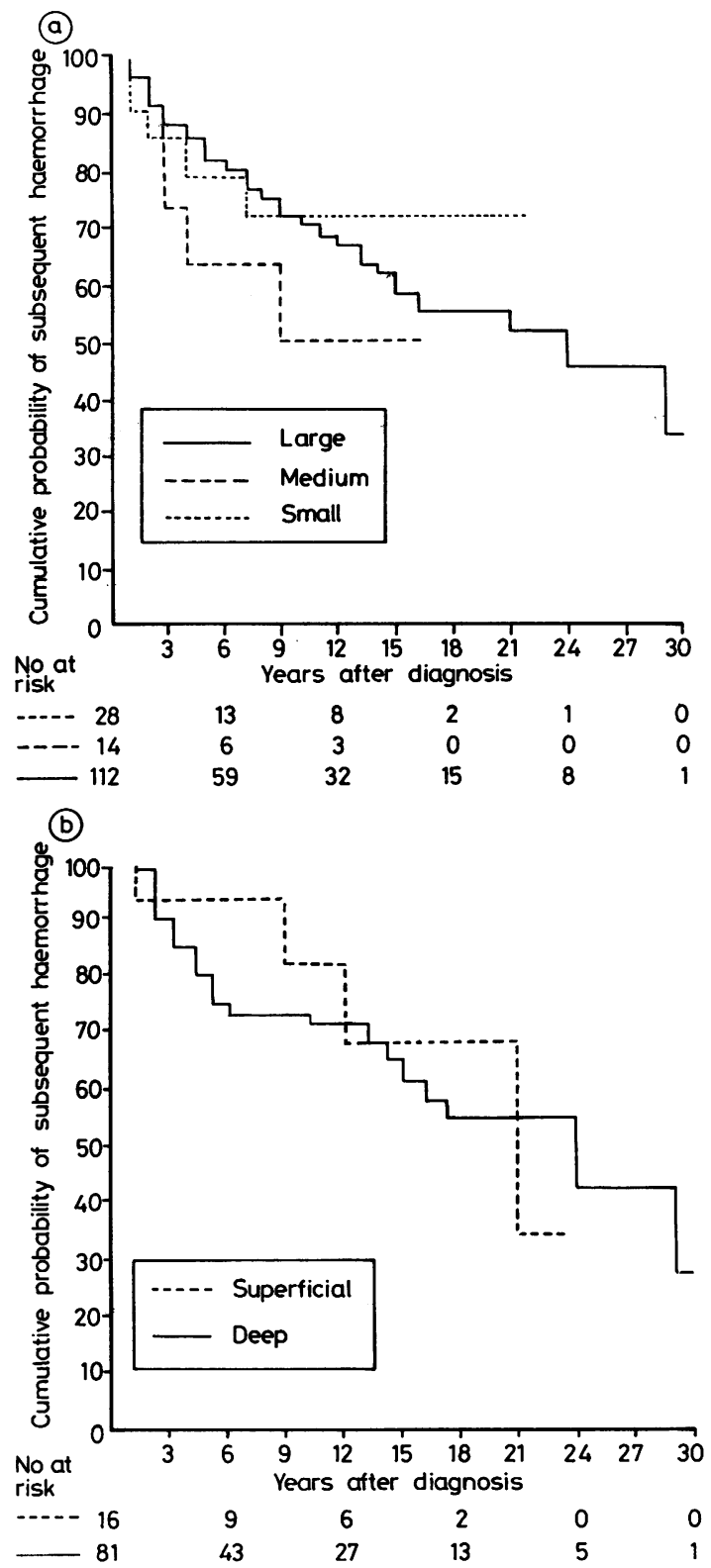

Fig 5 (a) Risk of haemorrhage in varying sizes of arteriovenous malformations. (b) Risk of haemorrhage and depth of arteriovenous malformation.

During follow up another 37 patients died, 24 from neurological causes related to their arteriovenous malformations. Nineteen died from a definite haemorrhage, one during a later operative removal of the lesion, one in status epilepticus, and three patients as a consequence of other undefined sequelae from their arteriovenous malformations. The cause of death in five patients was unrelated to 


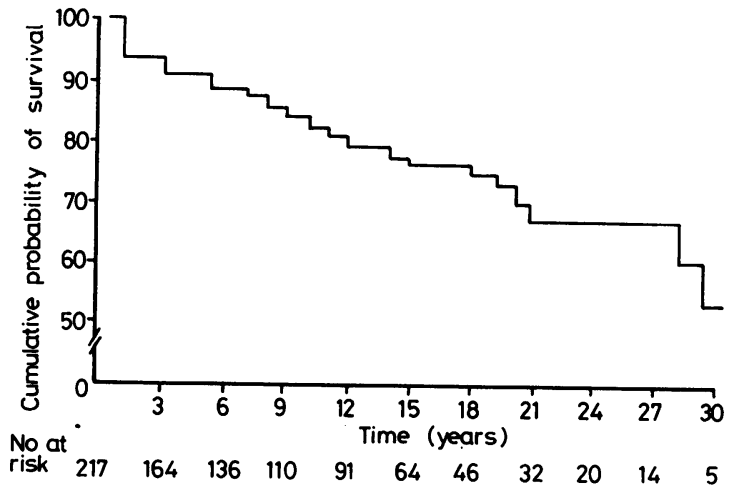

Fig 6 Risk of death from all causes during follow up.

the arteriovenous malformation, and in eight, was unkown.

The risk of death in patients presenting with haemorrhage (fig 7a) was $32 \%$ by 20 years ( $18 \%$ at 10 years) compared to $28 \%(20 \%-10$ years) for patients who had never bled. Thus the increased risk of rehaemorrhage in patients presenting with initial haemorrhage does not reflect itself in an increased mortality over 20 years (fig 7a and $b$ ). The risk of death from all causes over the same period for other diagnostic symptoms was $21 \%$ for those with epilepsy (17\%-10 years), $27 \%$ for those in whom the arteriovenous malformation was a coincidental finding (27\%-10 years), and $22 \%$ amongst those with neurological deficit (at 15 years).

Seventy-seven patients bled during follow up of whom $25 \%$ died as a result of the bleed.

Neither size nor depth affected the subsequent mortality $(p<0.02)$, but a malformation involving the parietal lobe carried a reduced risk $(25 \%)$ of death at 20 years $(15 \%$ at 10 years) compared with arteriovenous malformations at other sites $(p<0.05)$.

\section{Neurological disability}

Neurological disability may develop in two ways: an immediate neurological deficit resulting from an initial haemorrhage and late progressive neurological sequelae.

A. Early disability. Outcome was assessed at the time of discharge following diagnosis using the Glasgow Outcome Scale (table 11)." There was no significant difference between the outcome of the different diagnostic groups. Sixty two per cent of patients had no neurological handicap at the time of discharge, whilst another $25 \%$ had a minor neurological handicap. Only $6 \%$ of the patients had a major neurological deficit and were not capable of independent existence. Thus at the time of discharge nearly $90 \%$ of medically managed patients were independent and capable of work.

B. Late disability. The neurological syndromes occurring after diagnosis were divided into three major groups:

1. Neurological signs after haemorrhage during followup.

2. Progressive neurological signs from a "steal syndrome".

3. Hydrocephalus and its resulting problems.

Late neurological problems in the survivors were rare.
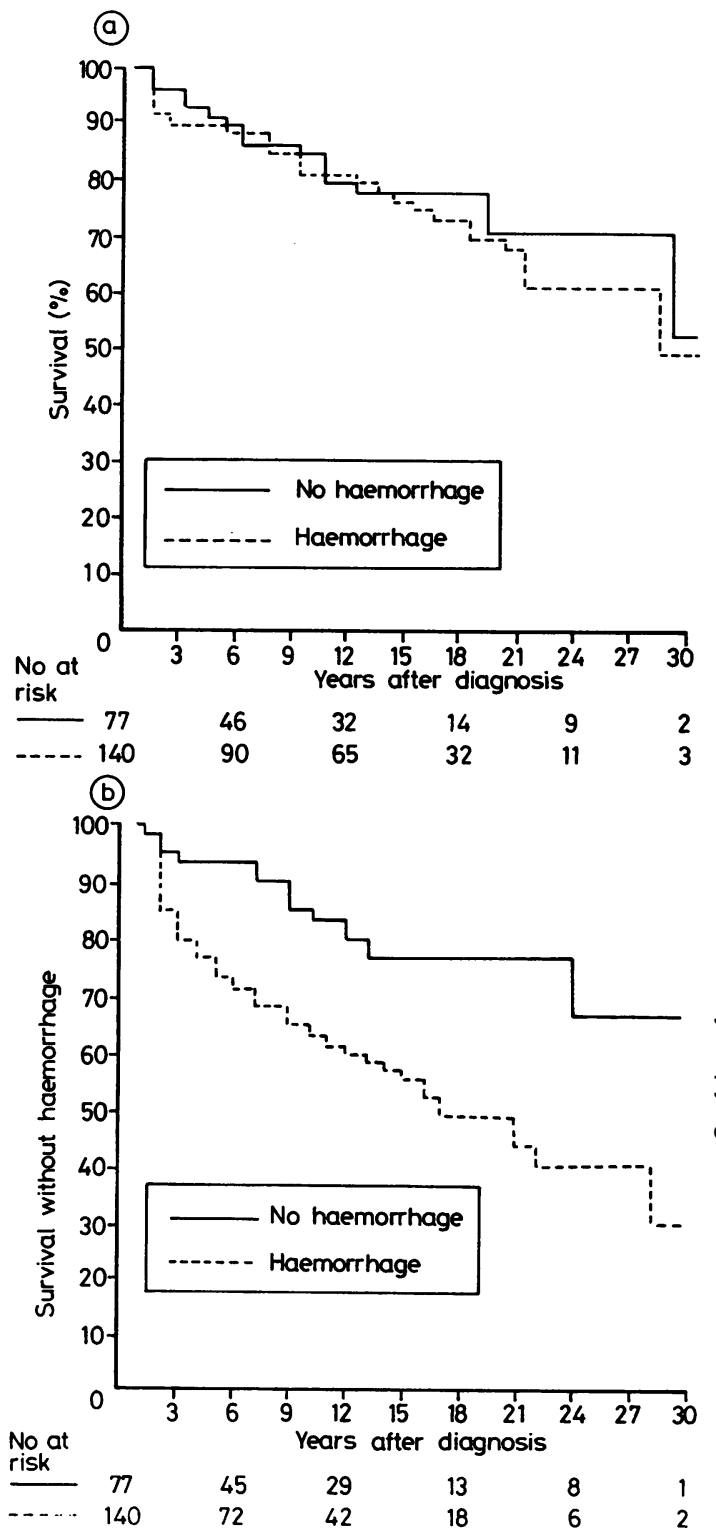

Fig 7 (a) Risk of death from all causes in patients presenting with and without haemorrhage. (b) Risk of haemorrhage during follow up in patients presenting with and without haemorrhage.

The risk of having a neurological handicap rose from $8 \%$ to $27 \%$ by 20 years (17\% at 10 years) (fig 8 ). Fifteen patients developed hemipareses secondary to subsequent haemorrhage, and six developed hydrocephalus. Two patients who had a residual hemiparesis from a haemorrhage, developed additional progressive neurological disability. One patient was severely incapacitated after a late 
Table 11 Outcome at discharge from hospital: untreated patients

\begin{tabular}{llcll}
\hline Grade & $\begin{array}{l}\text { Group 1 } \\
\text { haemorrhage }\end{array}$ & $\begin{array}{l}\text { Group 2 2 } \\
\text { epilepsy }\end{array}$ & $\begin{array}{l}\text { Group 3 } \\
\text { neurological } \\
\text { deficit }\end{array}$ & $\begin{array}{l}\text { Group 4 } \\
\text { other }\end{array}$ \\
\hline $\begin{array}{l}\text { Unknown } \\
\text { Death }\end{array}$ & 5 & 0 & 0 & 0 \\
$\begin{array}{c}\text { Persistent } \\
\text { vegetative }\end{array}$ & 7 & 1 & 0 & 1 \\
$\begin{array}{c}\text { state } \\
\begin{array}{c}\text { Severe } \\
\text { disability }\end{array}\end{array}$ & 0 & 0 & 0 & 0 \\
$\begin{array}{c}\text { Moderate } \\
\text { disability }\end{array}$ & 35 & 5 & 2 & 0 \\
No deficit & 86 & 7 & 12 & 1 \\
\hline
\end{tabular}

operation to remove an arteriovenous malformation. Thus in total 24 patients developed a late neurological handicap, but only six of these patients lost their independence.

The risk of late neurological handicap did not vary with symptoms at diagnosis, site, size or depth of an arteriovenous malformation.

\section{Late epilepsy}

At the time of diagnosis 143 patients in the non-operated group had never had an epileptic seizure. At 20 years after diagnosis the risk of epilepsy had reached $18 \%(11 \%$ at 10 years) (fig 9). In three patients this followed a late excision of the arteriovenous malformation. Nobody in whom the arteriovenous malformation was a coincidental finding, or who presented with a neurological deficit developed epilepsy within 20 years after diagnosis, compared with $22 \%$ (13\% at 10 years) of those presenting with haemorrhage $(\mathrm{p}<0.05)$.

Neither size nor depth of an arteriovenous malformation influenced the risk of developing de novo epilepsy. Women were at an increased risk of developing epilepsy compared to men $(p<0.02)$. Arteriovenous malformations involving the temporal lobe carried an increased risk (37\%) of developing epilepsy compared with an overall risk for other sites of $16 \%(p<0.14)$. This is not statistically significant but this might be due to the small number of

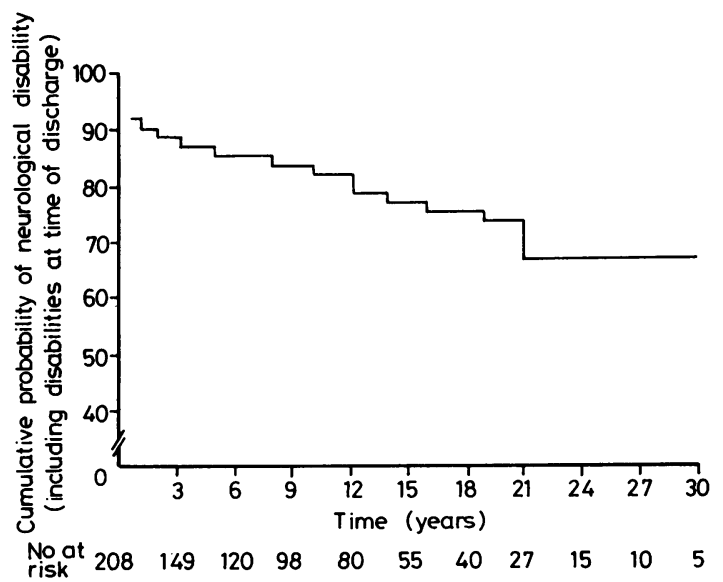

Fig 8 Risk of developing neurological disabilities including severe disability at the time of discharge.

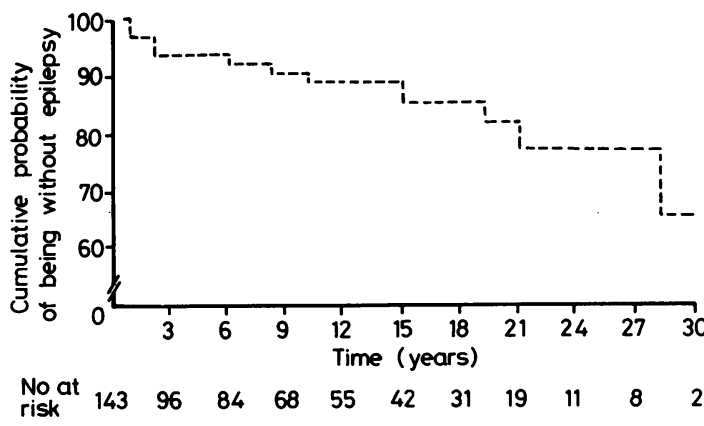

Fig 9 Risk of developing de novo epilepsy during follow up.

untreated patients with temporal arteriovenous malformations which had not been treated surgically (19 patients).

Age at diagnosis was important. The younger the patient was at diagnosis, the more likely were they to develop epilepsy during follow up. Patients aged 10 to 19 had a $44 \%$ risk, those aged 20 to 29 a $31 \%$ risk of developing epilepsy during the next 20 years compared to a risk of about $6 \%$ for those over the age of 30 . Nobody aged 60 years or over developed epilepsy during follow up ( $\chi^{2}$ for Trend $\mathrm{p}<0.02$ ).

\section{Discussion}

It is difficult to compare our data with previously reported studies because of the small numbers of untreated patients, short follow up and the surgical emphasis in the majority of other studies. Only five papers have more than fifty untreated patients ${ }^{12-16}$ and only two of these papers has median or average follow up of longer than five years. ${ }^{13}$ is One other paper uses life survival statistics to analyse some of their results. ${ }^{10}$

It is clear that the patients reported in studies of arteriovenous malformations vary considerably from study to study. This certainly reflects differing patterns of referral and variable bias in the proportion of patients offered surgical treatment. However the mode of presentation of our patients and characteristics of the arteriovenous malformations are similar to the majority of other large studies with less highly selected patients, in particular the Cooperative Study. ${ }^{12}$

One fact seems to merit discussion concerning the relationship of the mode of presentation and characteristics of the arteriovenous malformation and that is that patients with small lesions were more likely to present with haemorrhage as a major diagnostic symptom $(82 \%)$. This factor has been noted by many authors, ${ }^{16}$ but this study shows that a small arteriovenous malformation does not subsequently carry a higher risk of haemorrhage. Graf suggested patients with small arteriovenous malformations 
Table 12 Summary of prognostic factors

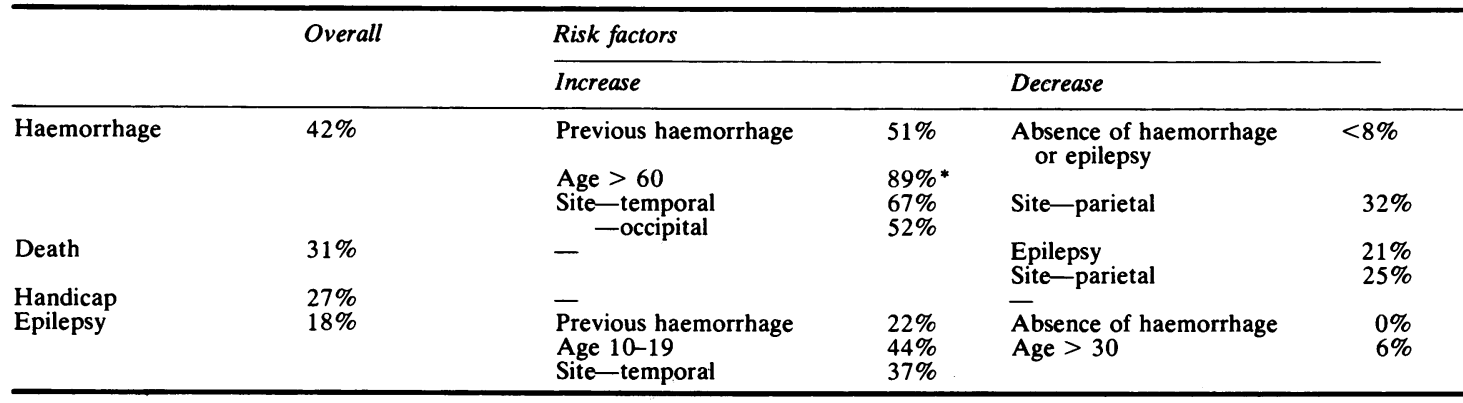

Percentages quoted are risks at 20 years; ${ }^{*}$ indicates the risk at 10 years.

have a $52 \%$ risk of rehaemorrhage and large arteriovenous malformations a $10 \%$ risk by five years after diagnosis $(p<0.05) . .^{16}$ These results contrast with ours as only $21 \%$ small and $18 \%$ large arteriovenous malformations rebled by 5 years. This may be due to the fact that Graf had only 12 patients with untreated small arteriovenous malformations. ${ }^{16}$ The apparent paradox of small arteriovenous malformations being more commonly found with a haemorrhagic presentation, but not causing a higher risk of subsequent rehaemorrhage, might be due to small arteriovenous malformations rarely causing epilepsy or other neurological symptoms before diagnosis. Thus small arteriovenous malformations might be quite common as asymptomatic anomalies in the general population. Indeed Courville quotes an incidence for arteriovenous malformations of 1:1000 necropsies. ${ }^{17}$

Our operative rate was low at $34 \%$. This rate is similar to Fults and Kelly's and other authors advocating conservative management (Svien $28 \%^{13}$ and Troupp $20 \%^{14}$ ). Many American centres quote higher operative rates of up to $94 \%,{ }^{18}$ which suggests that they report a more highly selected population of patients.

The data from follow up of our untreated patients are those of a selected population. Patients with untreated arteriovenous malformations tended to have larger and deep lesions, which were more posterior in situation and either in the left hemisphere or crossed the midline. The question arises as to whether we can apply the findings from our untreated patients to the group as a whole. The fact that neither the size nor depth of an arteriovenous malformation influences outcome suggests that this is not unreasonable. However the siting of arteriovenous malformations may have some influence on outcome and the more posterior siting of untreated lesions needs to be taken into account, although we doubt that it is likely to have a major effect on our results.
The factors influencing outcome are summarised in table 12 . The risk of subsequent haemorrhage by 20 years after diagnosis was $42 \%$ in untreated patients. The incidence of subsequent haemorrhage in other reports varied from $18 \%^{16}$ to $29 \%^{19}$ but length of follow up was often unclearr or short.

The factors which influenced the risk of haemorrhage were: presentation with haemorrhage, age at diagnosis and less importantly the site of the arteriovenous malformation. Presentation witho haemorrhage carried the greatest risk. There was an intermediate risk for patients who had epilepsy as their major diagnostic symptom and only small risk for those presenting with neurological deficits. No patients in whom the arteriovenous malformation was a coincidental finding had a haemorrhage during the period of follow up. Graf using life survivak statistics reported a rebleed rate of $42 \%$ by 20 yearse in patients presenting with haemorrhage. ${ }^{16} \mathrm{He}$ sug $=$ gests there is approximately a $37 \%$ risk for patients presenting with epilepsy having a first haemorrhage during the next 20 years. ${ }^{16}$ In his series patients who presented without haemorrhage or epilepsy had a risk of haemorrhage of $45 \%$ in only 16 patients by 10 years compared to less than $8 \%$ in this study. Fults and Kelly ${ }^{15}$ reported a $67 \%$ incidence of rehaemorrhage over 15 years in those presenting with haemorrhage and a $27 \%$ incidence of bleeding in those presenting with seizures.

Older patients had an increased risk of haemorrhage during follow up. Graf reported similar findings. ${ }^{16}$ This is likely to be a real phenomenon as age at presentation does not influence the mode of presentation nor the selection for surgical treatment. This fact is worthy of recognition as it may be that age could be seen as a relative contraindication to surgical treatment.

Initial mortality among medically managed patients in our series was $4 \%$ (6\% for patients presenting with haemorrhage). Mortality figures quoted in other papers vary from $6 \%{ }^{20}$ to $20 \% .^{21}$ Our low 
initial mortality rate may reflect the fact that patients with symptomatic arteriovenous malformations are likely to be admitted first to a District General Hospital and then referred later to the Unit. Patients may die before referral, or patient's age or general condition may influence referral patterns. We have no way of knowing how this kind of selection may effect our results.

Mortality during follow up from all causes (including initial mortality) by 20 years after diagnosis was $29 \%$. Sixty-five per cent of these deaths were consequent upon the arteriovenous malformation and most commonly resulted from haemorrhage. Twenty-five per cent of patients who had a haemorrhage during follow up, died as a result of haemorrhage. This is similar to the mortality for a subsequent haemorrhage reported by Fults and Kelly, ${ }^{15}$ and is probably a more accurate figure than that of $6 \%$ for mortality from initial presenting haemorrhage for the reasons discussed. It was difficult to identify any factors influencing mortality but parietal arteriovenous malformations may carry a reduced risk.

The majority of our patients were free from neurological deficit at the time of discharge from hospital, whilst $25 \%$ had a minor handicap. The majority, therefore, were independent and capable of work at the time of discharge and remained so during follow up.

The risk of developing epilepsy during 20 year follow up was $18 \%$. No other study appears to have looked at the development of de novo epilepsy in untreated patients. Patients with haemorrhage had the greatest risk of developing epilepsy $(22 \%)$ and no patient who presented with either a neurological deficit or in whom the arteriovenous malformation was a coincidental finding, developed epilepsy during follow up. Arteriovenous malformations involving the temporal lobe had an increased risk (37\%) compared to other lobes $(16 \%)$.

This is a retrospective study and therefore suffers from all the inherent problems of such studies. In particular, bias may have been introduced into treatment groups and accurate follow up data may be more difficult to obtain. However, because of the inclusion of a large population of medically managed patients it represents the first major study of arteriovenous malformations, offering some indication of their natural history. It also uses life survival statistics to try and quantify the risks of subsequent neurological events.

Olivacrona wrote in 1948 "In the end, probably most, if not all, patients (with arteriovenous malformations) die of haemorrhage or are completely incapacitated". ${ }^{14}$ The feeling is commonly shared by many neurosurgeons and neurologists and may be influenced by their knowledge of the prognosis for aneurysmal subarachnoid haemorrhage. The natural history of patients suffering a haemorrhage from cerebral aneurysm is poor. Sixty per cent will be dead at 2 months and indeed of those who survive the first 24 hours $40 \%$ are dead within this time..$^{22}$ In those surviving 6 months the risk of rupture is between 3-4\% per annum and carries a mortality of $67 \% .{ }^{23}$ Our study shows that the prognosis for patients with arteriovenous malformations is therefore much better and this fact must be considered in the overall management of a patient with an arteriovenous malformation.

We are grateful to our neurosurgical, neurological and neuroradiological colleagues, past and present, for allowing us access to their patients.

\section{References}

' Krayenbuhl H, Yasargil MG. Das Hirnaneurysma. Basal: JR Geigy, SA, 1958.

${ }^{2}$ Olivacrona H, Ladenheim J. Congenital Arteriovenous Aneurysms of the Carotid and Vertebral Arterial Systems. Berlin: Springer-Verlag, 1957.

${ }^{3}$ Pool JL. Arteriovenous malformations of the brain. In: Vinten PJ, Brugen GW, eds. Handbook of Clinical Neurology. N Holland Publishing Company, New York, 1972:227-66.

${ }^{4} \mathrm{Pia} \mathrm{HW}$. The indications and contraindications for treatment or assessment in cerebral angiomas. In: Pia HW, Glieve JRW, eds. Advances in Diagnosis and Therapy. Berlin: Springer-Verlag, 1975:1-7.

5 Dandy WE. Arteriovenous aneurysm of the brain. Arch Surg 1928; 17: 190-243.

- Cushing H, Bailey P. Tumours arising from the Blood Vessels of the Brain. Angiomatous Malformations and Haemangioblastomas. Springfield: Charles C Thomas, 1928.

7 Tonnis W, Schiefer W, Walter W. Signs and symptoms of supratentorial arteriovenous aneurysms. J Neurosurg 1958; 15:471-80.

${ }^{8}$ Hill Bradford A. $\chi^{2}$ for trend. Ashcroft textbook of Medical Statistics London: Hodder \& Stoughton 1977:156-9.

${ }^{y}$ Lee E, Desu M. A computer programme for comparing $\mathrm{K}$ samples with right censored data. Computer Programmes in Biomedicine, 1972.

${ }^{10}$ Peto R, Pike MC, Armitage P. Design and analysis of clinical trials requiring prolonged observation of each patient. II: Analysis. Br J Cancer 1977;35:1-39.

" Jennett B, Bond M. Assessment of outcome after severe brain damage: a practical scale. Lancet $1975 ; 1: 480-4$.

12 Perret G, Nishioka H. Report on the cooperative study of intracranial aneurysms and subarachnoid haemorrhage. Section VI. Arteriovenous Malformations. $J$ Neurosurg 1966;25:467-90.

${ }^{13}$ Svien HJ, McRae JA. Arteriovenous anomalies of the brain. Fate of patients not having definitive surgery. $J$ Neurosurg 1965;23:23-8. 
14 Troupp H, Marttila I, Halonen V. Arteriovenous Malformations of the Brain: prognosis without operation. Acta Neurochirurgica 1970;22:125-8.

${ }^{15}$ Fults D, Kelly DL. Natural history of Arteriovenous Malformations of the Brain: a clinical study. Neurosurgery 1984;15:658-62.

${ }^{16}$ Graf GJ, Perret GE, Torner JC. Bleeding from cerebral arteriovenous malformations as part of their natural history. J Neurosurg 1983;58:331-7.

${ }^{17}$ Courville CB. Pathology of the Nervous System, 2nd ed. Mountain View, California: Pacific Press Publ Ass, 1945.

${ }^{18}$ Moody RA, Poppen JL. Arteriovenous malformations. J Neurosurg 1970;32:503-11.

${ }^{19}$ Forster DMC, Steiner L, Hakanson S. Arteriovenous malformations of the brain. A long term clinical study. $J$ Neurosurg 1972;37:562-70.

${ }^{20}$ Pellettieri L. Surgical versus conservative treatment of intracranial arteriovenous malformations. Acta
Neurochir 1980;Suppl 29:1-36.

${ }^{21}$ Abad JM, Alvarez F, Manrique M, Garcia-Blazquez M. Cerebral arteriovenous malformations: comparative results of surgical vs conservative treatment in 112 cases. J Neurosurg Sci 1983;27(3):203-10.

${ }^{22}$ Alvord EC, Loeser JD, Bailey WL, Copass MK. Subarachnoid Haemorrhage due to ruptured aneurysms. A simple method of estimating prognosis. Arch Neurol 1972; 27:273-84.

${ }^{23}$ Winn HR, Richardson AE, Jane JA. Long term prognosis in untreated cerebral aneurysms: a 10 year evaluation of 304 patients. Ann Neurol 1977;1:358 69.

${ }^{24}$ Guidetti B, Delitala A. Intracranial arteriovenous malformations. J Neurosurg 1980;53:149-52.

${ }^{25}$ Parkinson D, Bachers G. Arteriovenous malformations. A summary of 100 consecutive supratentorial cases. $J$ Neurosurg 1980;53:285-99. 